Pesq. Vet. Bras. 36(8):787-792, agosto 2016 DOI: $10.1590 / \mathrm{S} 0100-736 \mathrm{X} 2016000800018$

Tópico de Interesse Geral

\title{
Células-tronco derivadas do epitélio olfatório: perspectivas terapêuticas na medicina veterinária ${ }^{1}$
}

\author{
Rosane Mazzarella², Taismara K. Garnica², Kelly C.S. Roballo²* e Carlos E. Ambrósioº
}

\begin{abstract}
Mazzarella R., Garnica T.K., Roballo K.C.S. \& Ambrosio C.E. 2016. [Stem cells derived from olfactory epithelium: therapeutic perspectives in veterinary medicine.] Células-tronco derivadas do epitélio olfatório: perspectivas terapêuticas na medicina veterinária. Pesquisa Veterinária Brasileira 36(8):787-792. Departamento de Medicina Veterinária, Faculdade de Zootecnia e Engenharia de Alimentos, Universidade de São Paulo, Av. Duque de Caxias Norte 222, Pirassununga, SP 13635-900, Brazil. E-mail: kellyroballo@gmail.com

The olfactory epithelium (OE) is a promising source of stem cells (OESC) for therapeutic use in veterinary and human medicine, especially in diseases correlated with the peripheral (spinal cord) and central (brain and brainstem) nervous system (CNS), because of its ability to differentiate into neurons, astrocytes and oligodendrocytes cells. In humans, OESC has been used primarily in therapeutic trials for degenerative diseases such as Alzheimer and Parkinson. In animals, the frequency of corresponding cases of chronic or acute neurodegenerative diseases is very low, because of the difficulty of a definitive diagnosis; thus, the focus of cell therapy research are mostly mechanical spinal cord injuries. Due to the lack of normalization and selection of the best methodologies for comparative studies, this review aims to analyze recent reports on the potential use of stem cells from the olfactory epithelium in cell therapies and to discuss the main challenges and future prospects in veterinary medicine.
\end{abstract}

INDEX TERMS: Olfactory epithelium, stem cell, spinal cord therapies, veterinary medicine.

RESUMO.- 0 epitélio olfatório (EO) é uma fonte promissora de células-tronco (CTEO) para o uso terapêutico na medicina veterinária e humana, especialmente em doenças correlacionadas com o sistema nervoso periférico (medula espinhal) e central (cérebro e tronco encefálico), pois as CTEO possuem a capacidade de se diferenciar em células do sistema nervoso, tais como: neurônios, oligodendrócitos e astrócitos. Em humanos estas células são utilizadas em ensaios terapêuticos de doenças degenerativas como o Alzheimer e Parkinson. Em animais a casuística relativa das doenças neurodegenerativas crônicas ou agudas é baixa, devido à dificuldade de diagnóstico definitivo, desta forma o enfoque das pesquisas com terapia celular são em sua grande maioria em lesões mecânicas na medula espinhal. Devido à falta de padronização e seleção das melhores metodologias que permitam confrontação de estudos, esta revisão busca

\footnotetext{
${ }^{1}$ Recebido em 5 de fevereiro de 2016.

Aceito para publicação em 3 de maio de 2016.

${ }^{2}$ Departamento de Medicina Veterinária, Faculdade de Zootecnia e Engenharia de Alimentos (FZEA), Universidade de São Paulo (USP), Av. Duque de Caxias Norte 222, Pirassununga, SP 13635-900, Brasil. *Autor para correspondência: kellyroballo@gmail.com
}

reunir as mais recentes publicações, descrevendo o potencial uso das células-tronco do epitélio olfatório em terapias celulares, discutindo os principais desafios e perspectivas futuras com enfoque na medicina veterinária.

TERMOS DE INDEXAÇÃO: Epitélio olfatório, célula-tronco, terapias na medula espinhal, medicina veterinária.

\section{INTRODUÇÃO}

A mucosa olfatória é composta por uma variedade de células, sendo subdividida em epitélio olfatório e lâmina basal. No epitélio olfatório estão localizadas as células basais horizontais e globosas, bem como receptores maduros e imaturos de neurônios. A lâmina basal possui em sua composição células da glia (macroglia ou glia radial) e as células-tronco mesenquimais (Duan \& Lu 2015).

0 epitélio olfatório se origina da região neural anterior através dos placódios olfatórios. Placódios são regiões de espessamentos do ectoderma que surgem a partir da placa neural durante o desenvolvimento dos órgãos sensoriais no período embrionário. Os placódios olfatórios são precursores do EO e dão origem aos neurônios olfativos, assim como as células de sustentação, glia radial e células neu- 
roendócrinas do tecido olfatório. Em associação aos placódios está o tecido pré-neural que posteriormente formará o bulbo olfatório, local responsável pela percepção do olfato (Carlson 1996).

Os neurônios olfativos localizados no EO possuem capacidade de regeneração diferenciada que perdura durante a vida adulta, indicando que parte deste tecido é constituída por células-tronco progenitoras (Duan \& Lu 2015). A maioria das células-tronco presentes nesse tecido se origina do ectoderma e são multipotentes. Estudos comprovam que essas células podem se diferenciar em três tipos celulares clássicos do sistema nervoso, como: neurônios, oligodendrócitos e astrócitos; sendo, portanto, eletivas para o uso na terapia celular no tratamento de doenças crônicas, progressivas ou degenerativas relacionadas ao sistema nervoso central (SNC) e periférico (Pagano et al. 2000).

A obtenção das CTEO é feita através de biópsia com acesso intranasal quando há a possibilidade de transplante autólogo, como descrito em roedores e humanos (Pagano et al. 2000), ou pela coleta de células após a decapitação e exposição da região de interesse, possibilitando o xenotransplante, como por exemplo, o transplante de células-tronco do epitélio olfatório de suínos em ratos com lesão de medula espinhal (Radtke et al. 2010). A caracterização das células-tronco é realizada a partir da utilização de marcadores moleculares e técnicas especificas de cultivo celular (Pagano et al. 2000).

Na medicina humana as células-tronco do EO são utilizadas em ensaios terapêuticos em doenças neurodegenerativas, tais como: a esclerose múltipla, Alzheimer, Parkinson e esquizofrenia (Escada et al. 2009). As células-tronco neuronais também são avaliadas quanto ao seu potencial de reparação de tecidos para a aplicação na medicina regenerativa em humanos (Escada et al. 2009).

Na medicina veterinária há poucas doenças descritas e diagnosticadas corretamente que levam a degeneração nervosa de maneira crônica ou progressiva. A grande maioria delas origina-se de lesões por traumas mecânicos ou acidentes automobilísticos e possuem localização na medula espinhal. Dentre as doenças neurodegenerativas podemos citar a cinomose canina na qual o vírus é capaz de desmielinizar os neurônios causando uma reação inflamatória no sistema nervoso central, levando a danos irreparáveis aos animais que sobrevivem à doença (Scarpelli 2008). Mais recentemente podemos citar como doença neurodegenerativa a atrofia e degeneração cortical superficial idiopática que assim como na cinomose até o momento não possui tratamento específico, contando apenas com o tratamento paliativo (Cahalan et al. 2014, Pinheiro et al. 2016). Outro exemplo é a ataxia hereditária canina, sendo considerada uma doença neurodegenerativa ocasionada por mutações e com maior prevalência em animais de raça pura (Urkasemsin 2014).

Desta maneira, o objetivo dessa revisão de literatura é descrever o uso potencial das células-tronco do epitélio olfatório em terapias celulares na medicina veterinária através de uma abordagem comparativa e translacional com a medicina humana.

\section{Principais métodos de coleta das células-Tronco do epitélio olfatório}

Há diferentes metodologias para a coleta e o isolamento das CTEO, sendo dependentes da espécie (animais domésticos ou de laboratório) e do objetivo terapêutico.

Em animais de laboratório, como os ratos e coelhos, a coleta pode ser realizada após a decapitação por via intranasal. Esse método deve seguir as normas bioéticas vigentes para o procedimento de eutanásia. Na coleta realizada após a decapitação, o maxilar inferior e os músculos faciais devem ser removidos a partir da parte anterior dos incisivos, também se deve remover o osso etmoide que cobre a cavidade nasal (Girard et al. 2011, Ercolin et al. 2016). Localizadas na parte medial do nariz com coloração laranja/marrom, as conchas nasais ficarão visíveis e também devem ser descartadas. No septo, a mucosa olfatória deve ser cortada ao longo de três locais: no arco da lâmina horizontal, na lâmina cribriforme e no teto da cavidade nasal. 0 procedimento de coleta em ambos os lados da cavidade nasal não deve ser superior a 10 minutos e o material coletado deve ser transferido para placas contendo meio de cultivo específico para a remoção do muco (Girard et al. 2011, Ercolin et al. 2016). Para que não se faça necessário à eutanásia e posteriormente o descarte dos ratos doadores, Stamegna et al. (2014) desenvolveu um método que permite a coleta em animais vivos. Nessa técnica a coleta é feita com um micro fórceps inserido através de uma pequena abertura no osso frontal permitindo o acesso a mucosa olfatória que está localizada na porção anterior a lâmina cribriforme.

Em animais domésticos a coleta de tecido contendo CTEO pode ser através da biópsia como foi descrito por Overall e Arnold (2007) em cães, sendo um método simplificado e pouco traumático. Para a análise das células-tronco neuronais (primordiais), estes mesmo autores coletaram amostras de tecido da lâmina nasal de aproximadamente $4 \mathrm{~mm}$ com o auxílio de fórceps para biópsia nasal. Antes do procedimento os cães foram anestesiados e aplicaram-se coagulantes, para redução de sangramento. De acordo com este estudo, para melhorar a qualidade das amostras estas devem ser coletadas em um plano uniforme com ângulo e profundidade constantes. Um procedimento semelhante ao descrito anteriormente, também foi utilizado em necropsia de fetos caninos (Alves 2009), onde foi coletado o tecido da lâmina cribriforme etmoidal em condições estéreis para o isolamento e cultivo das CTEO, de 1 a 2 horas post-mortem.

\section{Isolamento, cultivo e caracterização das células-tronco do epitélio olfatório}

O isolamento das células-tronco do epitélio e da lâmina própria é feito através de digestão enzimática ou mecânico. 0 epitélio olfatório pode ser removido da lâmina própria utilizando uma micro espátula, ou com o auxílio de bisturi. Assim que a lamina própria é isolada, realiza-se o procedimento de digestão enzimática ou mecânica, e a lâmina é então transferida para uma placa de Petri contendo meio de cultivo apropriado, sendo o meio mais comumente utilizado o DMEM (Dulbecco's Modified Eagle Medium) em conjunto com soro fetal bovino e antibióticos. Assim inicias-se o cultivo e então as CTEO podem ser utilizadas e estudadas. 
No caso de isolamento das CTEO em ratos, o tecido coletado é dissociado pela ação de enzimas (colagenase ou tripsina) e posterior centrifugação, dando origem a um pellet suspenso que será cultivado em meio suplementado com $10 \%$ de soro fetal bovino e antibióticos (Girard et al. 2011). Em 5 a 7 dias as células-tronco começam a expandir na placa de cultivo e após duas semanas se observa confluência de $70 \%$ a $80 \%$, o que permite a passagem e transferência das células para outra placa de cultivo ou sua criopreservação (Girard et al. 2011). Entretanto em cães após 24h utilizando a mesma técnica de isolamento, no cultivo se observa células com morfologia esférica ao redor de fragmentos aderidos e após 20 dias a presença principalmente de células epitelioides e fusiformes (Alves 2009).

Diferentes estratégias de análises de expressão de proteínas específicas podem ser utilizadas para caracterizar as CTEO e provar que as células cultivadas possuem plasticidade. Tais como a expressão de Nestin (proteína marcadora de células neuronais primordiais) e S100A4 (proteína expressa na progressão do ciclo celular e diferenciação, e produzida e alta quantidade em células-tronco do epitélio olfatório humano) através de técnicas de imunocompatibilidade como imunocitoquímica (Stamegna et al. 2014). Na citometria de fluxo analisa-se marcadores para caracterização de células-tronco como o HLA-DR, HLA-ABC, CD44, CD45, CD73, CD117 e CD105 (Alves 2009). Teste de imunofluorescência utilizando anticorpos como o Oct-4, Cytokeratin 18 ou Integrina $\beta 1$ e marcadores de células precursoras neurais como por exemplo GFAP (proteína glial fibrilar) e oligodendrócitos também podem ser utilizados para a caracterização celular (Alves 2009).

\section{Diferenciação das células-tronco do epitélio olfatório para A terapia celular}

A diferenciação celular pode ser realizada utilizando meios de cultivo que estimulam a diferenciação osteogênica, adipogênica ou neurogênica (Ercolin et al. 2016). Alves (2009) utilizou nas células-tronco provenientes de cães com 60 dias de vida intra-uterina, 2-fosfato ácido ascórbico e $\beta$-Glicerolfosfato para diferenciação osteogênica, para a diferenciação adipogênica utilizou-se meio de cultivo com dexametasona, indometacina, IBMX (3-isobutil-1-metilxantina), insulina, e na diferenciação neurogênica apenas monoetilglicerol (3-mercapto-1,2-propanediol). Em outro estudo realizado por Ercolin et al. (2016) com coelhos, utilizou-se também monoetilglicerol na diferenciação neuronal e meios de diferenciação comercializados na diferenciação osteogênica e adipogênica.

A diferenciação de células-tronco olfatórias em células neuronais também pode ser realizada cultivando-as durante 21 dias em meio neurobasal contendo B-27, antibióticos, glutamina e glutamato (Girard et al. 2011), bem como, em meio de cultivo contendo indutores como: FGF (fator de crescimento de fibroblasto) e TGF-B (fator transformador de crescimento $\beta$ ). Contudo, estudos indicam que diferentes fatores como FGF e TGF-B possuem ação positiva ou negativa nos diferentes estágios de diferenciação neurogênica, o que pode interferir na resposta desejada quando utilizadas em terapias celulares (Kawauchi et al. 2004).

\section{Aplicações terapêuticas das células-tronco do epitélio olfatório}

Por manterem certa memória celular características do tecido nervoso, após a diferenciação, as CTEO podem dar origem às demais células do sistema nervoso, tais como: astrócitos, oligodendrócitos e neurônios (Barnett \& Chang 2004). Por esse motivo o foco da pesquisa e aplicação dessas células está na reparação de injúrias situadas no tecido nervoso, tanto central (cérebro e tronco encefálico) quanto periférico (medula espinhal) (Krolewski et al. 2011). Apesar do uso na regeneração de lesões medulares em humanos, carecem de mais estudos na medicina veterinária com enfoque em animais domésticos.

Contudo, há diversos estudos com animais de laboratórios que já demonstram resultados satisfatórios (Quadro 1). Recentemente foram publicadas pesquisas com uma nova abordagem para o uso das células-tronco do epitélio olfatório, no tratamento de dor neuropática e terapia gênica em neoplasias. Esses dados nos revelam um grande potencial de plasticidade e aplicabilidade dessas células (Duan \& Lu 2015).

\section{Aplicações na reabilitação da função motora após res- secção total da medula espinhal}

Segundo experimento conduzido por Bambakidis et al. (2010) a implantação concomitante de células-tronco neurais associadas com células-tronco da mucosa olfatória, na medula espinhal, promove a proliferação e diferenciação dos neurônios, proporcionando reparação tecidual com melhoria no prognóstico. Nesse estudo foram utilizados ratos com lesão cerebral (hematoma intracraniano) com perda das funções motoras e que após serem submetidos ao tratamento tiveram sua capacidade motora restaurada. Em outro experimento conduzido por Lu et al. (2002), também com ratos, foi demonstrado à eficácia da reparação de tecido e a promoção do crescimento axonal após transplante autólogo de células-tronco do epitélio olfatório em ressecção da medula espinhal. Esse estudo foi conduzido por um período de quatro semanas, sendo suficiente para comprovar os resultados e a eficácia do tratamento na reparação tecidual e na promoção do crescimento axonal.

Em outros estudos as células da glia cultivadas a partir do epitélio olfatório foram transplantadas em ratos com lesão na medula espinhal e obteve-se melhora na regeneração e no reestabelecimento das funções motoras (Raisman 2007). Células-tronco do epitélio olfatório também foram estudadas na recuperação funcional de roedores com lesões crônicas e agudas no SNC devido à capacidade destas células de estimular ao mesmo tempo o tecido de neuroproteção, aumentar o crescimento de axônios e sua remielinização, ativar angiogênese e alterar a resposta da glia (Richter \& Roskams 2008).

Em uma meta-análise conduzida por Liu et al. (2014) foram avaliados 95 estudos relacionando o transplante das células-tronco do epitélio olfatório na regeneração motora após transecção completa de medula em roedores. Nessa pesquisa foi possível comprovar o efeito desse tipo de terapia através da análise estatística da literatura evidenciando o potencial dessas células. 
Em estudo conduzido por Feitosa (2011), as CTEO de coelhos foram utilizadas em transplante homólogo em animais com lesão medular induzida por hemissecção. Após 20 dias as CTEO implantadas foram rastreadas a partir da expressão de GFP (proteína verde fluorescente) atráves de técnica de imunohistoquímica comprovando o sucesso do transplante.

\section{Aplicação em lesões de medula espinhal}

Embora células-tronco neurais tenham capacidade de diferenciação em células do sistema nervoso central como as células da glia, apenas a sua aplicação não é suficiente para o reparo da medula espinhal (Ao et al. 2007). Apesar de regular o processo inflamatório e a formação de matriz extracelular ela possui baixo potencial regenerativo (Paviot et al. 2011). Por isso há a necessidade de melhorar este processo que pode ser realizado em conjunto com outra terapia celular, melhorando o suporte imunomodulatório da lesão. Ao et al. (2007) mostrou o efeito sinérgico promovendo regeneração neuronal e funcional da medula espinhal através de células-troncos neurais em combinação com células-tronco do epitélio olfatório. 0 transplante combinado com fibroblastos olfatórios também mostrou resultados positivos ( Li et al. 2005).

\section{Aplicações no tratamento de dor neuropática e de do- enças neurodegenerativas crônicas}

Zhao et al. (2015) realizou o tratamento da dor neuropática de nervo ciático através do uso dessas células. Neste estudo foram transplantados implantes de células-tronco do epitélio olfatório envolvidas em microcápsulas de ácido algínico no local da lesão seguido de avaliação da resposta à dor nos animais. Após 14 dias de tratamento pode-se evidenciar os benefícios da terapia celular. Os autores sugerem que as microcápsulas com as células suprimem a expressão de $\mathrm{P} 2 \mathrm{X} 2 / 3$ um receptor encontrado nas raízes nervosas entre as vértebras lombares (L4-5). Esse trabalho proporciona uma nova perspectiva de abordagem quanto ao uso dessas células em terapias regenerativas.

De acordo com Nivet et al. (2011), ratos com lesão no hipocampo tiveram neuroplasticidade recuperada após o tratamento por xenotransplante com células-tronco do epitélio olfatório humano. Outros estudos mostraram melhoras no comportamento e nas lesões do corpo estriado de ratos utilizados como modelo animal para o estudo de Parkinson (Murrell et al. 2008, Wang et al. 2012). Células globosas basais são células-tronco presentes no epitélio olfatório que embora sua função ainda precise ser mais bem estudada, são importantes para a manutenção do epitélio olfatório (Suzuki et al. 2013) e em condições ideais in vitro elas possuem capacidade de autorenovação e diferenciação em células da glia e neurônios (Beites et al. 2005).

\section{Aplicações em células tumorais}

Há também a utilização em terapia gênica para indução de apoptose em células tumorais, sendo que no estudo realizado por Hashemi et al. (2015) elucidou a capacidade de migração, tropismo celular e não rejeição do implante dessas células. 0 ensaio conduzido teve como objetivo avaliar o potencial tumoricida do gene tiamidina cinase de herpes vírus simplex (HSV-tk) em glioblastoma multiforme humano (GBM). Os pesquisadores concluíram que as células do epitélio olfatório que carreavam o gene (OECs-tk) foram capazes de migrar pela cultura de células de glioblastoma multiforme humano e afetar a taxa de sobrevivência das

Quadro 1. Aplicações terapêuticas das células-tronco do epitélio olfatório

\begin{tabular}{|c|c|c|c|c|}
\hline Origem das células & $\begin{array}{c}\text { Modelo } \\
\text { Experimental }\end{array}$ & $\begin{array}{l}\text { Lesão/Célula envolvida na } \\
\text { terapia celular }\end{array}$ & Resultados obtidos & Referência \\
\hline $\begin{array}{l}\text { Células-tronco neurais associadas a } \\
\text { células-tronco da mucosa }\end{array}$ & Ratos & Lesão cerebral (hematoma intracraniano) & $\begin{array}{l}\text { Proliferação e diferenciação de } \\
\text { neurônios }\end{array}$ & Tang et al. (2010) \\
\hline $\begin{array}{l}\text { Células-tronco do epitélio olfatório } \\
\text { (transplante autólogo) }\end{array}$ & Ratos & Ressecção da medula espinhal & $\begin{array}{l}\text { Reparação de tecido e a promoção } \\
\text { do crescimento axonal }\end{array}$ & Lu et al. (2002) \\
\hline Células-tronco do epitélio olfatório & Ratos & Transecção completa de medula & Potencial na regeneração motora & Liu et al. (2014) \\
\hline \multirow[t]{2}{*}{ Células-tronco do epitélio olfatório } & Coelhos & Lesão medular induzida por hemissecção & Células-tronco do epitélio & Feitosa (2011) \\
\hline & & medular dorsal & $\begin{array}{l}\text { olfatório } 20 \text { dias após o } \\
\text { transplante }\end{array}$ & \\
\hline $\begin{array}{l}\text { Células da glia cultivadas a partir do } \\
\text { epitélio olfatório }\end{array}$ & Ratos & Lesão na corda espinhal & $\begin{array}{l}\text { Melhora na regeneração e no } \\
\text { reestabeleciomento de funções }\end{array}$ & Raisman (2007) \\
\hline Células-tronco do epitélio olfatório & Ratos & Lesões crônicas e agudas no SNC & Recuperação funcional & $\begin{array}{l}\text { Richter \& Roskams } \\
\text { (2008) }\end{array}$ \\
\hline $\begin{array}{l}\text { Células-troncos neurais em combi } \\
\text { nação com células-tronco do epitélio } \\
\text { olfatório }\end{array}$ & Ratos & Lesão da medula espinhal & $\begin{array}{l}\text { O efeito sinérgico promovendo } \\
\text { regeneração neuronal e funcional }\end{array}$ & Ao et al. (2007) \\
\hline $\begin{array}{l}\text { Células-tronco do epitélio olfatório } \\
\text { envolvidas em microcápsulas de } \\
\text { ácido algínico }\end{array}$ & Ratos & $\begin{array}{l}\text { Lesão por constrição crônica } \\
\text { do nervo ciático }\end{array}$ & $\begin{array}{l}\text { Benefícios da terapia na resposta } \\
\text { a dor neuropática de nervo ciático }\end{array}$ & Zhao et al. (2015) \\
\hline $\begin{array}{l}\text { Células-tronco do epitélio olfatório } \\
\text { humano }\end{array}$ & Ratos & Lesão no hipocampo & Recuperação da neuroplasticidade & Nivet et al. (2011) \\
\hline Células globosas basais & Ratos & Lesões do corpo estriado & $\begin{array}{l}\text { Melhoras no comportamento } \\
\text { de ratos modelo para estudo de } \\
\text { Parkinson }\end{array}$ & $\begin{array}{l}\text { Murrell et al. (2008) } \\
\text { Wan et al. (2012) }\end{array}$ \\
\hline $\begin{array}{l}\text { Células do epitélio olfatório que } \\
\text { carreavam o gene (OECs-tk) }\end{array}$ & Humano & Glioblastoma multiforme humano (GBM) & $\begin{array}{l}\text { Células } \\
\text { geneticamente são capazes de } \\
\text { induzir a apoptose em células } \\
\text { tumorais }\end{array}$ & Hashemi et al 2015 \\
\hline
\end{tabular}


células tumorais de acordo com o tempo de exposição e concentração do quimioterápico ganciclovir. 0 que sugere que essas células modificadas geneticamente são capazes de induzir a apoptose em células tumorais.

\section{Principais desafios e perspectivas na medicina vete- rinária}

Embora estudos mostrem o potencial terapêutico destas células, sua utilização apresenta alguns fatores de risco. 0 primeiro que pode ser citado é que a garantia de segurança do uso destas células foi comprovada somente em transplantes autólogos (Goni et al. 2014), ficando a ressalva da utilização das CTEO em transplantes não autólogos. 0 segundo fator de risco importante é a formação de tumores em animais e humanos após o transplante celular (Seminatore et al. 2010, Duan \& Lu 2015). Por isso, o controle proliferativo, de sobrevivência, migração e diferenciação após transplante são pontos que precisam ser melhores elucidados.

O uso das células-tronco do epitélio olfatório na terapia celular e especialmente na recuperação de lesão de medula espinhal tem demonstrado resultados positivos na literatura consultada. Porém deve-se levar em conta o método de isolamento, ou seja, quais os tipos celulares envolvidos, os protocolos utilizados para implante dessas células, com especial atenção ao uso de terapias concomitantes que possibilitam vieses de interpretação nos ensaios, bem como, superestimação de resultados. E devemos ressaltar que não há ainda um protocolo a ser seguido, ou seja, há ainda a falta de padronização que permita a confrontação dos estudos e a seleção da melhor metodologia (Raisman 2001). Outro ponto a ser discutido é também o efeito dos transplantes de células-tronco em humanos, já que os resultados in vivo são estritamente relacionados a modelos animais experimentais, na maioria das vezes ratos ou coelhos. Deve-se levantar o mesmo questionamento sobre o benefício do uso em animais de companhia, pois os resultados efetivos ainda são desconhecidos. Em um dos únicos estudos relacionado à utilização das CTEO na veterinária foi realizado em cães, e o transplante autólogo dessas células se tornou limitado por conta da dificuldade de acesso cirúrgico para a biopsia nasal, resultado da característica anatômica do focinho da espécie canina (Salazar et al. 2015).

\section{CONSIDERAÇÕES FINAIS}

Atualmente, os danos na medula espinhal ou no sistema nervoso central são causados principalmente pela perda de células por degeneração ou injúrias incuráveis. Dessa maneira, buscam-se alternativas que regenerem tais tecidos de forma minimamente invasiva. Neste contexto as células-tronco do epitélio tem se tornado fundamental como fonte terapêutica devida sua capacidade neurogênica. Entretanto devido ao procedimento invasivo necessário para a coleta do EO e das CTEO, a realização do transplante autólogo é de difícil realização em animais domésticos, resultando em certa limitação do seu uso como terapia celular. Sendo assim, o método mais utilizado é o transplante homólogo ou o xenotransplante. Porém para que tais estudos utilizando CTEO como terapia celular possam ser praticados na rotina clínica da medicina veterinária, pesquisas mais aprofundadas e padronizadas são necessárias para o melhor entendimento dos diferentes tipos de célula-tronco presentes no epitélio nasal, da função de cada tipo celular durante a neurogênese, da purificação destas células, assim como para análiseda real viabilidade do cotransplante com células-tronco de origens diferentes.

Agradecimentos.- À Fundação de Amparo a Pesquisa do Estado de São Paulo (FAPESP), pelo apoio e suporte financeiro (Processo №: 2015/17897-9).

\section{REFERÊNCIAS}

Alves F.R. 2009. Avaliação da cultura de células-tronco do epitélio olfatório de cães sem raça definida (Canis familiaris Linnaeus, 1758 ). Tese apresentada ao Programa de Pós- Graduação em Anatomia dos Animais Domésticos e Silvestres da Faculdade de Medicina Veterinária. 138p.

Ao Q., Wang A.J., Chen G.Q., Wang S.J., Zuo H.C. \& Zhang XF. 2007.Combined transplantation of neural stem cells and olfactory ensheathing cells for the repair of spinal cord injuries. Med. Hypotheses. 69(6):1234-1237.

Bambakidis N.C., Wang X., Lukas R.J., Spetzler R.F., Sonntag V.K. \& Preul M.C. 2010. Intravenous hedgehog agonist induces proliferation of neural and oligodendrocyte precursors in rodent spinal cord injury. Neurosurgery. 67(6):1709-1715.

Barnett S.C. \& Chang L. 2004. Olfactory ensheathing cells and CNS repair: going solo or in need of a friend? Trends in Neurosci. 27(1):54-60.

Beites C.L., Kawauchi S., Crocker C.E. \& Calof A.L. 2005. Identification and molecular regulation of neural stem cells in the olfactory epithelium. Exp. Cell Res. 306(2):309-316.

Cahalan S.D., Cappello R., De Lahunta A. \& Summers B.A. 2014. A Novel Idiopathic Superficial Neocortical Degeneration and Atrophy in Young Adult Dogs. Veterinary Pathology. 52(2):344-350.

Carlson B.M. 1996. Embriologia Humana e Biologia do Desenvolvimento. Guanabara Koogan, Rio de Janeiro. 269p.

Duan D. \& Lu M. 2015. Olfactory mucosa: a rich source of cell therapy for central nervous system repair. Rev. Neurosci. 26(3):281-293.

Escada P.A., Lima C. \& Da Silva J. M. 2009. The human olfactory mucosa. Eur Arch Otorhinolaryngol. 266 (11):1675-1680.

Ercolin A.C., Roballo K.C., Casals J.B., Pieri N.C., Souza A.F., Barreto da R.S., Bressan F.F., Feitosa M.L., Miglino M.A., Meirelles F.V. \& Ambrósio C.E. 2016. Rabbit olfactory stem cells. Isolation protocol and characterization. Acta Cir. Bras.1(31):59-66.

Feitosa M.L.T. 2011. Terapia Celular com Células-Tronco em Coelhos com Lesão Medular Induzida e em Cães com Lesão Medular Crônica Espontânea. Tese apresentada ao Programa de Pós- Graduação em Anatomia dos Animais Domésticos e Silvestres da Faculdade de Medicina Veterinária. 118p.

Girard S.D., Devéze A., Nivet E., Gepner B., Roman F.S. \& Féron F. 2011. Isolating nasal olfactory stem cells from rodents or humans. J. Vis. Exp. 54:1-5.

Goni V.G., Chhabra R., Gupta A., Marwaha N., Dhillon M.S., Pebam S., Gopinathan N.R. \& Kantharajanna S.B. 2014. Safety profile, feasibility and early clinical outcome of cotransplantation of olfactory mucosa and bone marrow stem cells in chronic spinal cord injury patients. Asian Spine J. 8(4):484-490.

Hashemi M., Fallah A., Aghayan H.R., Arjmand B., Yazdani N., Verdi J., Ghodsi S.M., Miri S.M. \& Hadjighassem M. 2015. A New Approach in Gene Therapy of Glioblastoma Multiforme: Human Olfactory Ensheathing Cells as a Novel Carrier for Suicide Gene Delivery. Mol. Neurobiol. 1-11.

Kawauchi S., Beites C.L., Crocker C.E., Wu H.H., Bonnin A., Murray R. \& Calof A.L. 2004. Molecular Signals Regulating Proliferation of Stem and Progenitor Cells in Mouse Olfactory Epithelium. Dev. Neurosci. 26(2-4):166180.

Krolewski R.C., Jang W. \& Schwob J.E. 2011. The generation of olfactory epithelial neurospheres in vitro predicts engraftment capacity following 
transplantation in vivo. Exp. Neurol. 229(2):308-323.

Li Y., Field P.M. \& Raisman G. 2005. Olfactory ensheathing cells and olfactory nerve fibroblasts maintain continuous open channels for regrowth of olfactory nerve fibres. Glia. 52(3):245-251.

Liu J., Chen P., Wang Q., Chen Y., Yu H., Ma J., Guo M., Piao M., Ren W. \& Xiang L. 2014. Meta analysis of olfactory ensheathing cell transplantation promoting functional recovery of motor nerves in rats with complete spinal cord transection. Neural Regen. Res. 9(20):1850-1858.

Lu J., Féron F., Mackay-Sim A. \& Waite P.M. 2002. Olfactory ensheathing cells promote locomotor recovery after delayed transplantation into transected spinal cord. Brain. 125(Pt 1):14-21.

Murrell W., Wetzig A., Donnellan M., Féron F., Burne T., Meedeniya A., Kesby J., Bianco J., Perry C., Silburn P. \& Mackay-Sim A. 2008. Olfactory mucosa is a potential source for autologous stem cell therapy for Parkinson's disease. Stem cells. 26(8):2183-2192.

Nivet E., Vignes M., Girard S.D., Pierrisnard C., Baril N., Devèze A., Magnan J., Lanté F., Khrestchatisky M., Féron F. \& Roman F.S. 2011. Engraftment of human nasal olfactory stem cells restores neuroplasticity in mice with hippocampal lesions. J. Clin. Invest. 121(7):2808-2820.

Pagano S.F., Impagnatiello F., Girelli M., Cova L., Grioni E., Onofri M., Cavallaro M., Etteri S., Vitello F., Giombini S., Solero C.L. \& Parati E.A. 2000. Isolation and characterization of neural stem cells from the adult human olfactory bulb. Stem cells. 18 (4):295-300.

Paviot A., Guérout N., Bon-Mardion N., Duclos C., Jean L., Boyer O. \& Marie J.P. 2011. Efficiency of laryngeal motor nerve repair is greater with bulbar than with mucosal olfactory ensheathing cells. Neurobiol. Dis. 41(3):688-694.

Pinheiro A.O., Cardoso M.T., Vidane A.S., Casals J.B., Passarelli D., Alencar A.L.F., Sousa R.L.M., Fantinato-Neto P., Oliveira V.C., Lara V.M. \& Ambrósio C.E. 2016. Controversial results of therapy with mesenchymal stem cells in the acute phase of canine distemper disease Genet. Mol. Res. 15 (2):gmr.15028310.

Overall K.L. \& Arnold S.E. 2007. Olfactory neuron biopsies in dogs: A feasibility pilot study. Appl. Anim Behav. Sci. 105:351-357.

Radtke C., Lankford K.L., Wewetzer K., Imaizumi T., Fodor W.L. \& Kocsis J.D. 2010. Impaired spinal cord remyelination by long-term cultured adult porcine olfactory ensheathing cells correlates with altered in vitro phe- notypic properties. Xenotransplantation. 17:71-80.

Raisman G. 2007. Repair of spinal cord injury by transplantation of olfactory ensheathing cells. C. R. Biol. 330(6-7):557-560.

Raisman G. 2001. Olfactory ensheathing cells - another miracle cure for spinal cord injury? Nat. Rev. Neurosci. 2(5):369-375.

Richter M.W. \& Roskams A.J. 2008. Olfactory ensheathing cell transplantation following spinal cord injury: Hype or hope? Exp. Neurol. 209(2):353-367.

Salazar I., Barrios Santos W.A., Zubizarreta A. \& Sánchez Quinteiro P. 2015. Harvesting of olfactory ensheathing cells for autologous transplantation into the spinal cord injury. Its complexity in dogs. Front Neuroanat. 9:110.

Seminatore C., Polentes J., Ellman D., Kozubenko N., Itier V., Tine S., Tritschler L., Brenot M., Guidou E., Blondeau J., Lhuillier M., Bugi A., Aubry L., Jendelova P., Sykova E., Perrier A.L., Finsen B. \& Onteniente B. 2010. The postischemic environment differentially impacts teratoma or tumor formation after transplantation of human embryonic stem cell-derived neural progenitors. Stroke. 41(1):153-159.

Scarpelli EM. 2008. Encephalomyelitis in Canine Distemper: Prospective Study of Clinical, Histological and RT-PCR findings. Tese ao Programa de Pós-Graduação em Ciências Médicas da Unicamp.

Stamegna J.C., Girard S.D., Veron A., Sicard G., Khrestchatisky M., Feron F. \& Roman F.S. 2014. A unique method for the isolation of nasal olfactory stem cells in living rats. Stem Cell Res. 12(3):673-679.

Suzuki J., Yoshizaki K., Kobayashi T. \& Osumi N. 2013. Neural crest-derived horizontal basal cells as tissue stem cells in the adult olfactory epithelium. Neurosci. Res. 75(2):112-120.

Urkasemsin G. \& Olby N.J. 2014. Canine Hereditary Ataxia. Vet. Clin. North. Am. Small Anim. Pract. 44(6):1075-1089.

Wang M., Lu C. \& Roisen F. 2012. Adult human olfactory epithelial-derived progenitors: a potential autologous source for cell-based treatment for Parkinson's disease. Stem Cells Transl. Med. 1(6):492-502.

Zhao H., Yang B.L., Liu Z.X., Yu Q., Zhang W.J., Yuan K., Zeng H.H., Zhu G.C., Liu D.M. \& Li Q. 2015. Microencapsulation improves inhibitory effects of transplanted olfactory ensheathing cells on pain after sciatic nerve injury. Neural Regen. Res. 10(8):1332-1337. 